\title{
The Theoretical Framework, Methods, and Layout of the Research
}

Our research into how the espoused theologies of African Christian students and academics in French-speaking Africa can contribute to the global science and religion debate leads us into little-explored territories of research. Therefore, it also necessitates critical reflection on the question of which methodological approaches are best suited to both the field of study and our research objectives. This chapter discusses the methodological decisions we arrived at as a result of the interplay between our research interests and theoretical framework, and the need to do justice to the unique research contexts and the specific research requirements that we formulated. Ultimately, the research methodology is justified if it enables new and significant insights into the realities that are studied. Examples of even relatively comparable projects were limited, and so our approach was mainly inductive.

In the first section of this chapter, we look at our understanding of 'intercultural theology' as the most essential part of the theoretical framework. We discuss the notion and place of 'culture' that is so central to this relatively new theological enterprise, and we explain what makes this a theological approach. Furthermore, we elaborate on why we expect that our intercultural and theological approach will contribute valuable insights to the science and religion debate that are not limited to particular cultural contexts, and why they are valuable even to those who work with different theological presuppositions than those that underlie this project.

In the second section of this chapter we explain our choice of discourse analysis and the use of Group Model Building as the principal research tool. Due to our expectation that insights from French-speaking Africa would provide valuable new perspectives for the global science and religion debate, and particularly the Western section of that debate, we were automatically invited to study the 'ordinary', 'lived', or 'espoused' theologies of relevant groups. So far, little has been written in the traditional format of academic texts from a francophone African perspective (see the exceptions mentioned in Chapter 1: Makanzu 1986; Bame Bame 1994); yet, there are good reasons to suppose that some of the most relevant insights are to be found in discourses about science and religion among Christian students and academics. However, up until now, these valuable insights have not yet been mined and made available for broader 
intercultural debates. We made use of Group Model Building, which is a specific participatory research method often employed by management studies to understand decision making in groups. As we explain below, Group Model Building is particularly apt for enabling this discourse to crystalize in a manner that allows the participants to retain ownership of their discourse without unnecessary outside intervention.

In the third section of this chapter, we describe the concrete layout of the research process which took place in three different locations and was spread across a number of research visits. We also explain the choices made about gathering and analysing the data, share some of the challenges encountered in the process, and discuss the lessons learned for future intercultural theology research projects on science and religion and beyond.

\section{An Intercultural Theological Approach to Science and Religion}

As indicated in Chapter 1, there is a growing awareness that the way in which different communities and thinkers approach questions about science and religion is deeply influenced by their cultural (and therefore also geographical) locations. This project not only originated from this observation but has also tested and confirmed the thesis that culture is a crucial factor in this debate. It has shown that a particular cultural location may allow for new insights into the understandings of science and religion. Furthermore, these insights also lay bare cultural blind spots caused by the fact that every cultural standpoint (including Western culture) invites or even forces people to look at these questions from specific angles, in a particular light, and given unspoken assumptions that remain hidden in the background.

Therefore, the cultural factor in the science and religion debate invites us to an intercultural dialogue. In our understanding there are a number of vital components to successful dialogue. First, one must make the effort to understand alternative perspectives not in terms of one's own cultural and conceptual framework, but according to their proper structure and integrity.

Intercultural theology thus has a strong hermeneutical component (cf. Wrogemann 2016; Schreiter 1997, 28ff.). Furthermore, dialogue requires that one does not treat others as mere objects of study. We cannot limit ourselves to simply describing alternative positions that represent interesting cultural phenomena, but rather we must accept that these positions and people may become conversation partners. They can only become conversation partners (rather than people to be studied, educated, or tolerated) if we presuppose 
that they may offer genuine insights into the same realities we are studying, which we may have thus far missed because of our cultural standpoint.

In our own experience, such genuine intercultural dialogue is very challenging to achieve as it requires significant hermeneutical skills and patience to understand cultural perspectives that are profoundly different from one's own. A complicating factor is that in a number of areas of life a sense of cultural superiority is so deeply ingrained that we are hardly aware of it. One does not need to opt for complete cultural relativism to ask critical questions here. Rather, we need to realise that while culture can allow for true insights, cultural short-sightedness or even blindness is by definition very hard to spot in oneself. Modern scientific approaches to reality have been very successful in the West. The modern scientific worldview has gained such a powerful cultural dominance in the North Atlantic world that it has become the cultural reality against which the value of many other aspects of our own culture are measured. As researchers with many years of service in Central Africa and Latin America, we probably have a greater sense of the relativity of North Atlantic cultural and social perspectives than some others, and yet it was all too easy to approach our conversation partners with attitudes that could confirm or strengthen a sense of superiority in regard to science. We were deeply impressed by a number of our conversation partners, but visiting Abidjan, Yaoundé, and Kinshasa - three leading university cities in French-speaking Africa there were moments when we were shocked by the weakness of the academic infrastructure, and by the regular lack of what we might call 'genuine academic interest' or 'science for the sake of science'. Stories about magical events that we would often label as 'superstitious' in the West were shared on a regular basis with little of the critical distance that we as Westerners would expect. At times it took conscious effort to realise that these cultural and social realities might be an opportunity for us to have insights that we cannot come by so easily precisely because of the limitations of the dominant scientific approach in our own context.

It is clear that genuine intercultural engagement with questions of science and religion (and with all truly significant questions that address broader and deeper life issues) not only demands proper research tools, but also the continuing development of the researchers in terms of their attitude and outlook. Knowledge is always deeply personal (cf. Polanyi 1962; Jaeger 1999, 26-43) and " $[t]$ he self is not some kind of virus which contaminates the research. On the contrary, the self is a research tool, and is thus intimately connected to the methods we deploy" (Cousin 2010, 10). Apart from the importance of the attitude, experiences, and outlook of the researcher, we also need to critically 
examine a number of concepts that are central to this project, and ask whether and how they can be a help rather than a hindrance to intercultural dialogue and exploration. In the following subsections we focus on the two terms that are crucial in an intercultural theological approach: culture and theology. We also introduce the notion of triangulation, a key building block for understanding the relationship between the two.

\subsection{The Value and Limitations of the Notion of Culture}

In this study we explore the way in which the science and religion debate is influenced by the cultural context in which it plays out. In order to do so well, we need an understanding of culture that is appropriate to address this question. This concept of culture will need to be distinguished from the 'integrated' understanding of culture that was developed in the 1920 in cultural anthropology - or, more precisely, that accompanied and made possible the development of cultural anthropology as an academic discipline - and that remained very influential even when it came under growing criticism in the 1970 and afterwards. In this integrated understanding, a culture is conceived as an integral whole that covers all aspects of life and that has a strong coherence around some integrative principle. A culture is associated with a social consensus that is shared by specific social groups (often, but not necessarily, ethnic groups) that can be distinguished from other groups with relative ease. Culture therefore stresses human diversity, and allows one to see radically different and potentially incommensurable ways of life as fundamentally having equal value - this is in sharp contrast to the cultural evolutionism that characterised the earlier period (Tanner 1997, 25ff.; Schreiter 1997, 47ff.; Kim 2016).

However, the integrated concept of culture does not do justice to the fact that cultures are not homogeneous and harmonious wholes, but normally present inner tensions; they are not sealed off from other cultures, but are rather in constant interaction with other cultural influences; they are not static but are a space for continuing negotiation and development. This more 'postmodern' notion of culture with its stress on "interactive process and negotiation, indeterminacy, fragmentation, conflict and porosity" (Tanner 1997, 38) reveals the complex nature of traditional societies, but is even more necessary and apt for our globalising world characterised by cultural interaction and cultural flows. This notion of culture is particularly helpful for studying and analysing discourse on science and religion in our research population. The cultural interactions in these contexts reveal tensions and negotiations both within cultural streams and between cultural streams (that include modern Western, traditional African, and also Christian influences). Intercultural exchange and dialogue dos not take place between neatly separated cultural compartments, 
but are an important part of contemporary life, which is characterised by cultural hybridisations (cf. Schreiter 1997, 74-78).

In reflecting on the value of the concept of culture, we also need to understand its limitations. To paraphrase a Dutch theologian's reflection on politics (Kuitert 1986), we can say that "everything is culture, but culture is not everything." In focussing on intercultural interactions, there is a risk of making 'culture' an all-encompassing category in terms of which all aspects of the interaction are explained. ${ }^{1}$ One cause of this tendency is that the concept is introduced by cultural anthropology, which, as a matter of disciplinary integrity, makes it the dominant category through which analysis and interpretation take place. Nevertheless, the need to recognise the potential limits of the explanatory power of 'culture' is a given with intercultural dialogue. If one wants to take other cultural insights seriously, one also needs to realise that others may use different categories for what anthropologists refer to as 'culture' or may use the notion of culture or related terms in a different way. The all-encompassing use of 'culture' as a category for analysis and explanation is, of course, a specifically Western academic practice, although not one that is universally shared even in the West. As we explain below, this understanding does not fit our realist approach. Additionally, in intercultural encounters such a use of culture risks imposing a foreign category. When some practice or belief is explained as 'cultural' while from another cultural perspective, in that particular culture the practice or belief may not be seen as 'merely' cultural, but rather as a form of 'religion', 'morality', or 'science' (or their approximate cultural or linguistic equivalents). This is not to say that such beliefs or practices are not also part of culture (they are), but it means that they are not 'merely' or only cultural for the community itself. Therefore, study and dialogue only become genuinely intercultural if one takes these other perspectives into account.

How do we then understand culture in this book and in our perception of intercultural theology? As we will see in Chapters 4 and 5 , the participants mainly use 'culture' in its modern, anthropological, or what Schreiter calls 'integrated' understanding. Sometimes this understanding is even restricted to ethnicity. Expressions such as 'African culture' and 'Western culture' are to be understood as characterizing societies and sometimes peoples. In the reconstruction of the discourses we stick to this use of 'culture'. However, our own understanding of culture is more open than the classic anthropological perceptions. In Chapter 6 we develop an understanding of intercultural theology that is based on anthropologist Joel Robbins' (2017) approach to culture and

1 See for an interesting parallel debate from the intercultural study of mental illness: Oloyede 2002b; Ventevogel 2002; Oloyede 2002a. 
the central role of transformation when it comes to Christian cultural engagement. Robbins keeps a modern understanding of culture as his point of departure but argues that Christian faith leads to transformation of culture. This perspective also offers a better understanding of the participants' beliefs, especially those of the students from Yaoundé who are searching for a proper African Christian understanding of science (Chapter 5). Under the conditions mentioned above, which exclude an all-encompassing and closed or integrated understanding, we accept a classic anthropological definition of culture, like that of Tylor:

Culture, or civilization, taken in its wide, ethnographic sense, is that complex whole which includes knowledge, belief, art, morals, law, custom, and any other capabilities and habits acquired by man as a member of society.

TYLOR 1958, 1

\subsection{The Need for a Theological Approach}

In this section we explain why we opt for a theological study of the discourse on science and religion in Christian communities in French-speaking Africa, and then explain their contribution to the wider science and religion debate. Of course, the data and interpretations presented in this study offer a wealth of material on cultural interactions and negotiations in contemporary subSaharan Africa that is also unique from a social science perspective. However, we are interested in cultural understandings of science and religion, more specifically science and the Christian faith, not only to better understand how people in different communities engage with these two domains, but also because we are interested in the question of science and religion itself and how the scientific and religious perspectives relate. What is the value and interrelation of both ways of knowing, of both ways of relating to the world? This is a theological question, because it concerns questions about whether and how the God Christians believe in is related to the world that is the object of scientific research.

We would claim that every position one takes in this respect is inherently theological, even if one opts for a radical Wittgensteinian approach to science and religion which sees both discourses as having integrity and value in themselves, but as unrelated to each other and unrelated to an 'extralinguistic reality' (Barbour 2000, 19-22). This approach presupposes theological convictions concerning the unknowability of God and the incapability of language to adequately describe God. If these theological convictions cannot be affirmed (and if a parallel conviction about the nature of scientific language and its reference 
were not necessarily true), then one would need to consider the possibility that at least some theological language about God's relationship to the world can interact with scientific language. We will return to the question of the nature of theological language in its relation to reality in the following section on 'critical triangulation'.

At this point, it is important to clarify what we mean by 'theology' in this study, and especially the notion of 'espoused theology', which we use to refer to the discourse of the groups of students and academics. In this study we use 'theology in four voices', which is a description of theology borrowed from Helen Cameron et al. (2010). They distinguish between (a) 'normative theology', as the normative theological texts of a religious community, (b) 'formal theology', as the theological reflection and production in academic settings, (c) 'espoused theology', as the theological understanding of the members of the community, and (d) 'operant theology', as the theology that is implicit in the practices of the community (Cameron et al. 2010, 53-56). We focus on espoused theology because of our belief that African Christian communities might have very valuable insights to offer to an intercultural debate on science and religion, despite the fact that few of these insights have been formulated in 'formal theology' such as in academic theological texts. We opted for the study of the 'espoused' theology rather than the 'operant theology' of these groups because we thought that many of the relevant insights would be conscious within the community or could be adequately formulated by the community if given an appropriate setting such as Group Model Building or focus group sessions. In the course of the research, these beliefs have been justified.

It was less clear to us whether the 'operant theology', present in the day to day life of the community, could be adequately researched within the means available for this project. Furthermore, if we had opted for the study of 'operant theology', our respect for the agency of the community itself in the intended intercultural theological exploration would have meant that the community itself needed to be the primary interpreters of their operant theology. This interpretation would still need to happen in focus groups, which would be very similar to the group work in the current project. Studying the operant theology would, therefore, necessitate an extra step in the research with potentially relatively few additional insights gained. Such a study on 'operant theologies' of science and religion could potentially first be done in a Western setting where most empirical studies of these issues have taken place (cf. Howard Ecklund 2010; Guest et al. 2013).

Our study is an exercise in 'formal theology' and engages in academic theological reflection while using insights harvested from 'espoused theology'. This enterprise therefore presupposes a close relationship between formal and 
espoused theology. Theology is not seen as a top-down enterprise based on forms of reasoning (be they exegetical, philosophical, or doctrinal) that have little to do with the life of the Christian community and that might meet the community somewhere in the process of downward dissemination.

Academic theology as fides quaerens intellectum is a specialised activity within the community of faith that critically accompanies this community, and as such is at the service of both the community of faith and the wider society. This does not presuppose that the lived faith of the congregation (in religious experience, a life of discipleship or liberating action) is the primary locus of divine revelation, but we do recognize its revelatory function. The community of believers is called to faithfulness to God while discerning the guidance of the Spirit in relation to the cultural, social, and missional challenges it faces in its particular context. The high estimate we give to the espoused theology of the community also reflects the conviction that theologians are neither the first, nor necessarily the best-placed, persons to respond to God's selfrevelation. They do their academic work realising that this Trinitarian revelation demands a response by a community that lives out this faith, and to which it therefore needs to remain connected. Furthermore, the priority of this lived theology does not presuppose that the insights presented in the formal theology are only addressed to and valuable for the Christian community. While we are conscious of the fact that these insights are acquired within a specific tradition of reflection, they are still presented as 'public theology' with 'universal intent' (Polanyi 1962, 150, passim; Newbigin 1991).

This primacy of ordinary knowledge is not unique to theology but is characteristic of many and potentially all academic disciplines that present formalised enterprises representing ordinary human ways of knowing. In that sense, it reflects a naturalist epistemology, which considers epistemological reflection as taking off from a critical reflection on natural forms of knowing. However, such an epistemology does not mean that one opts for a naturalist metaphysics, and can well be combined with a 'supernaturalism' in metaphysics (Plantinga 1993, 194). This approach to academic knowledge is also appropriate in our research context. A number of students and academics pointed to both rudimentary and more developed forms of scientific knowledge in precolonial Africa as parallels to the Western scientific enterprise (cf. Feierman and Janzen 2011, 229ff.). ${ }^{2}$ If academic knowledge is indeed a systematic and

2 See Chapter 4, more specifically the contribution of Ayuk in the second part on the academics' discourse. 
formalised approach to natural ways of knowing, such parallels are not only apparent, but may be truly significant. ${ }^{3}$

\subsection{Critical Triangulation}

The last two sections may seem to point in different and potentially incompatible directions. The section on culture emphasises the cultural bedding of all thinking on science and religion and could easily suggest a social or cultural constructivist understanding of the science and religion discourse in these three university cities. On the other hand, the section on theology reveals the desire to use these insights in a theological debate on the nature of the relationship between science and religion (or more specifically the Christian faith). It argues that this debate is necessarily theological and implies a critical realist approach to reflection on how God relates to realities like science, Christian faith, and African traditions.

The 'critical' in critical realism is used as a qualifier to show that we do not presuppose a strict parallel between our language and reality. We simply presuppose that language describes a reality that exists before, and is independent of, the language used to describe it. Nevertheless, we recognise that language continually needs to be critically assessed with regards to the question of whether it adequately describes reality, how it does so, and how it can be adapted in order to allow for a better correspondence to this reality (McGrath 1999, 154-164).

Such a critical realist understanding is shared by a most (natural) scientists (Polkinghorne 1989, 162; Polkinghorne 1991, 5; McGrath 1999, 143, 154). As Michael Devitt writes, "If scientific realism, and the theories it draws on, were not correct, there would be no explanation as to why the observed world functions as if they were correct; that fact would be brute, if not miraculous" (Devitt 1984, 1; cf. Toren 2011, 122-127). Scientists encounter a robust reality which may not always fit their culturally embedded preconceived understandings of the nature of reality. As John Polkinghorne puts it, "Experimentialists do find it difficult to see what they are not expecting. [...] Yet one must also acknowledge that the stubborn facticity of nature imposes ineluctable constraint, whatever one might have anticipated would be the case" (Polkinghorne 1989, 169ff., 173). This is precisely why - though culture may be a critical factor in every human endeavour, including the scientific enterprise - culture cannot be the only explanation of the findings.

3 For a more recent example of how 'people's science' can provide scientifically valid insights, see a recent study by the anthropologist Paul Richards on the responses of West-African communities to the Ebola crisis (Richards 2016). 
We therefore combine the study of the cultural aspects of the science and religion debate with a critical realist understanding of the nature of science. Of course, this project does not focus on the primary data and theories of science. These are not beyond dispute, but critical debates focus much more on questions of the limits of science, of the extrapolations from scientific findings to questions of worldview, of what science might potentially miss, and on the relationship between scientific and religious insights into the nature of reality and life.

There are, of course, alternative understandings of science, particularly when science is studied from a social science perspective, as with the radical interpretation of Thomas Kuhn's classic work (Kuhn 1996). Nevertheless, the realist approach has wide traction in the current climate as far as (natural) scientific knowledge is concerned. Though the precise nature of the theological language does not generally become explicit in the discourses studied, a critical realist understanding is well placed to engage in an intercultural dialogue with the espoused theology expressed in these discourses. The academics and students involved would generally have beliefs about topics such as creation and how God acts today in miraculous healings. An intercultural theological approach that presupposes a critical realist understanding of theological language is therefore well placed to engage in a dialogue with these academics and students. ${ }^{4}$ Such a perspective allows for an approach that is more truly dialogical than approaches that would limit the analysis of the material to cultural and social perspectives. Any such approaches would thus end up presenting analyses and interpretations that would miss (theological) aspects of the conversation, which for the conversation partners are crucial and possibly the most significant issues at stake.

The exchange between different cultural perspectives envisaged in intercultural theology, and in this study, helps to mediate between these different understandings of reality, including different understandings of how reality can be known. In this respect, the notion of 'triangulation' is useful. This notion is used in epistemology by the philosopher Donald Davidson, with precisely the aim of overcoming the limitations of the particular location of the knowing subject. When discussing opposing views, two people point to the same reality, thus creating a triangle between the two observers and the third angle of the

4 Certain understandings of religious and theological language, such as the one developed by George Lindbeck (Lindbeck 1984) would, however, argue that there exists a crucial difference between first order language of faith and second or third order theological language. We would argue that the critical nature of theological language with regards to faith language implies a critical reflection on the degree in which it succeeds in its implicit references to reality. 
object to which they point. It is this triangle that allows one to critically consider one's own perception of the world and confirm the inter-subjectively perceived reality (e.g., Davidson 1991). Kevin Vanhoozer has extrapolated this notion to intercultural theological conversations, which allows one to critically test, confirm, and expand the theological understanding of one culturally located Christian community against another (Vanhoozer 2006). Thus, intercultural theology becomes a 'three-way conversation' in which the triangle formed between different participants, who discuss their understanding of God in his relation to the world, allows for a critical realist exchange (Toren $2015 \mathrm{c}$ ). This project engages in a dialogue between North Atlantic and sub-Saharan African understandings of the relationship between science and religion, thus allowing for a critical engagement with the complex reality that these different culturally located perspectives on science and religion seek to understand.

The notion of triangulation is also used in the social sciences: it refers to the methodological possibility of confirming certain findings, or gaining a fuller understanding of them, by studying the same social reality from different angles (with the same methods, different methods, different sources of information, or different researchers) (Denscombe 2014, 346-351). This kind of methodological triangulation also happens in this project through the use of different methods (surveys, Group Model Building, and focus groups) to study the espoused theology on science and religion in French-speaking Africa This methodological triangulation helps us to gain a better understanding of the discourse of African students and academics, one of the angles of the larger theoretical triangle described above representing the intercultural theological conversation.

One does not need to accept a critical realist understanding of theological language and reflection beforehand in order to engage in such an intercultural conversation. The question of what counts as adequate knowledge, and what this would mean for different types of discourse, can itself be the object of intercultural exchange, and must be if it concerns scientific and religious knowledge. True intercultural exchange means giving alternative understandings of the nature of scientific knowledge, of religious knowledge, and of the knowledge transmitted by other traditions, a fair hearing. Otherwise, the possibility of gaining new insights from an intercultural engagement on issues of science and religion grows thin.

Intercultural theological dialogue thus engages us in a double hermeneutical process: we engage in the process of understanding others with their symbolic systems that have their own coherence, tensions, and dynamics (Wrogemann 2016, xx). However, these symbolic systems, are not free-floating self-referential constructs. They are themselves responses to an extra-linguistic 
reality which shines through in these images, but which may also be deformed or even replaced by phantom worlds. The dialogue itself presupposes this triangle; it presupposes that we are speaking to a certain degree about the same realities, and it is this presupposition that helps us detect where our mutual understanding is hindered by our cultural embeddedness, and which helps us strive for a deeper understanding. In the process, we are therefore not only involved in a hermeneutic of alternative cultural understandings, but are also reading reality itself, precisely by comparing our own reading of reality with alternative readings (Toren 2011, 136-138). This process will also lead to a different understanding of ourselves and thus to a transformed engagement with the other and with reality. It is therefore clear that intercultural hermeneutics do have their place in hermeneutics of reality - and vice versa.

Finally, our understanding of intercultural theology in this study differs from an older approach that is mainly German in origin and is represented by Werner Ustorf, who understands himself to be in the line of Hans Jochen Margull, Walter Hollenweger, and Richard Friedli (Ustorf 2008). This approach fully recognizes the decisive role of the discovery of Christianity as a worldwide movement for the shape of theology in the current era. However, in contrast to our understanding of intercultural theology, this approach has propounded the view that "[n]on-Western forms of Christianity would develop their individual theological identities in response to the pressing issues of their social, political, religious and cultural contexts and are part of the general 'surge of the 'Third World' in world politics" (235). In Chapter 6, we will argue more extensively that this understanding tends to ignore the importance of the catholic character of the Christian faith. For that reason, we underline the crucial importance of a genuine dialogue with other Christian perspectives (cf. Toren 2015 c, 13off.) rather than the "post-Christian iconoclasm" of the West (Ustorf 2008, 242).

\section{Methodology: On Discourse Analysis and Group Model Building}

\subsection{Discourse Analysis}

We use discourse analysis, which is loosely defined by Stephanie Taylor as a "close study of language in use" $(2001,5)$, in order to investigate the oral contribution from French-speaking Africa. Although discourse analysis cannot be reduced to one single perspective or method, Louise Philips and Marianne Jørgensen argue that the variety of theories and instruments used in discourse analysis share some key characteristics. For example, these authors mention the assumption that "language is structured in patterns or discourses - there 
is not just one general system of meaning (...) but a series of systems or discourses, whereby meanings change from discourse to discourse" and "the maintenance and transformation of the patterns should therefore be explored through analysis of the specific contexts in which language is in action" (2002, 12). One of the main questions is whether the dominant discourse is perceived to be (absolutely) hegemonic or not. In a more classical understanding of discourse analysis there is no room left for alternatives to the dominant discourse. However, Bacchi points to theorists who leave "room for subjects to move within the constraints imposed by hegemonic discourses" $(2005,201)$. Norman Fairclough's Critical Discourse Analysis (CDA) follows suit on this point (Fairclough 2001). In this perspective, discourse is considered to be both "constitutive and constituted" (Philips and Jørgensen 2002, 66). Our research presupposes an understanding of discourse in line with Fairclough and Bacchi. Hence, we assume that the discourse of the research population may not be identical to the dominant (political) discourses in the cultural context of French-speaking Africa (which was shown to be the case). Therefore, subjects having 'room to move' is a crucial element of our understanding. This 'room to move' includes a 'use' of various discourses, which appears to be the case as the different groups produce different discourses. It is in this context that Bacchi's search for agency is relevant for our positioning. This also suits the theological focus of our study as we explained above.

Given our theological framework, we are also critical about the exclusive concentration on human power as the determining factor of social reality. Mechteld Jansen's (2011) intercultural pastoral theology helps us to highlight the way we understand our use of discourse. In her study of the exchange of life stories by people from different cultures she explicitly mentions the presence of God in the narratives. She does not claim that the narrative approach she uses reveals God. However, the author situates the 'images of revelation' in the space between the participants, and in the dynamics that take place when the experiences are shared (Jansen 2011, 118-122). Jansen relates this revelation more specifically to the Holy Spirit. This is in line with what we argued above when we pointed to the guidance of the Holy Spirit as sustaining the importance of espoused theology. We do not understand human agency as separate from this divine revelation, but rather as included, albeit without identifying human action with the divine.

Bacchi argues that the agency is to be located within the discourse, because discourse analysis does not perceive the subject outside the discourse (2005, 206). Here we come to a second critical interaction between discourse theories and our theological principles. What does it mean if the agency is limited to the discourse? Philips and Jørgensen (2002, 21-22) argue that this does not 
necessarily imply a constructivist understanding. These authors emphasise, however, that discourse analysis implies that there is no 'reality' behind the discourse. They perceive discourse and reality as being inseparable. Above, we underlined the importance of the assumption of reality as a 'third' aspect important for our understanding of intercultural theological. As discourses are culturally situated, the intercultural debate helps us to understand the relation between discourse and reality as being less tight than in Philips and Jørgensen's view. Our point is not to claim direct knowledge of reality, in this case God, but to underline that the assumed reality should not disappear, either in a constructivist negation or in a perspective in which discourse and reality cannot be distinguished. In our understanding, reality is a constitutive point of reference for the different dialogue partners.

\subsection{Working with Group Model Building}

In this study we research the way Christian MA students and academics from francophone Africa understand the relation between science and faith. Their debates on these topics are extremely important for the reconstruction of their arguments and positions. These debates are therefore the discourses we research. The literature on discourse analysis pays special attention to the role of patterns or conceptual schemas in the use of language. Expressions, word repetitions, similar relations between concepts, etc., are indications of a possible shared perspective. In our case we research oral material in order to discover the particularities and the convergences both within the discourses of every research group and between the different groups. We use the expression 'reconstruction of the discourse' in order to indicate that this is a group process in which the participants make decisions on a joint perspective without denying the diversity of opinions. Due to the crucial importance of the group process in the research we prefer to use a research instrument for groups. The group character of the research is especially helpful in African contexts, where theology is often developed in communal conversation (Munikwa and Hendriks 2011). The researchers involved had limited roles in the groups. Lynda and Klaas facilitated the Group Model Building sessions and Klaas facilitated the focus group sessions. However, the facilitating role, also makes one an outsider and a witness and sometimes Klaas felt invited to judge or to mediate. In some groups, the participants expressed their frustration about Klaas's 'impartial' or 'just facilitating' role, and this was especially true after the second research session which preceded the conference that was part of the formation track.

Additionally, because of our intercultural theological focus, we use a participatory research tool. Surveys or interviews are therefore less useful because these instruments are directed towards the individual and do not sufficiently 
safeguard the African origin and ownership of the reconstruction. We therefore prefer a participatory research instrument in which the power of the researcher is relatively small, and in which the group process is fully considered (De Roest 2015, 247-250). The cluster of methods we refer to with the term 'participatory research methods' is often related to Action Research and shows a certain family resemblance to the related method of Appreciative Inquiry. These methods are of particular value to intercultural theology because they help to address a number of issues related to the intercultural theological approach we mentioned in the first section of this chapter. In the first place, participatory research methods make Christian communities in other parts of the world conversation partners, rather than objects of research. In a similar fashion, these methods help to engage in a conversation between more academic theology and espoused and lived theology (cf. Toren 2015c, Toren and Bom 2018, Bom 2018). Finally, this method takes seriously the reality that many academic and educational institutions in the Global South have limited resources and interest in investing research in projects that have no direct practical relevance.

Group Model Building (GMB) is qualified as a participatory research instrument because it facilitates discourse analysis in a group while respecting the dynamics of the negotiation within the group and without the researchers steering the process (Luna-Reyes et al. 2006). GMB stems from the large family of System Dynamics-related research tools in the natural and social sciences. Bleijenbergh, Korzilius and Verschuren classify GM B as one of the participatory methods of practice orientated research (2011, 148-149). They distinguish between practice based and expert based participatory research. However, in our research we are not primarily interested in how experts perceive the situation of the debate in the three cities, but rather want to reconstruct and study the discourse of people with the experience of being Christian and studying or working at a university in these concrete situations. This does not completely exclude expert perception because all participants are, in a way, experts in their own academic disciplines and bring in a specific expertise of their discipline to the discussion of the relationship between science and faith. However, the dominant practical approach here implies engagement with what these authors call 'practice orientated research'. It is therefore directly related to a practical problem which is defined by these authors as "a problem that calls for an intervention or a new artefact in order to change reality in a desired direction" (Bleijenbergh, Korzilius and Verschuren 2011, 148). When GMB is used as a tool for discourse analysis, the reconstruction of the discourse can be perceived as such an artefact. According to these authors, this calls for decision making or strategic management $(2011,148)$. 
How does GM B work? Rouwette, Bleijenbergh, and Vennix describe the process as follows:

GMB involves a number of experts and other stakeholders in a series of face-to-face sessions. A facilitator and modeler help the participants to describe their situation in the form of a qualitative or quantitative system dynamics model.... The process via which GMB brings about these outcomes boils down to the elicitation of stakeholder's ideas and goals, confronting them with each other and with available data and combining them in an overall model.

Decision making support methods aim to increase open communication on messy problems in order to reach consensus on the problem at stake and coordination of the efforts of different stakeholders.

ROUWETTE, BLEIJENBERGH AND VENNIX, 2016, 64-65.

The expression 'messy problems' is often used in the GMB literature, especially by Vennix and the research group of Nijmegen Management Studies. Vennix perceives problems as messy when "people hold entirely different views on (a) whether there is a problem, and, if they agree there is a problem, (b) what the problem is" (Vennix 1996, 13, 49-51). Our research confirms that the relationship between science and Christian faith can be called a messy problem in this sense. Our data, the reconstructed discourses of six groups - one student group and one academic group in each of the three cities - leads us to conclude that the groups access science and Christian faith quite differently. For example, the groups have different understandings of the importance of cultural influences, and even within a group, there are differences on this topic, as is evidenced by the presentation of the debates in Chapters 4 and 5 .

As we argued in Chapter 1, the dominant understanding of science and religion is defined by the North Atlantic world, and, if we want to understand what Christians in francophone Africa think about it, it is important to understand how this theme is modelled in African concepts and understandings. GMB proved to be a useful research instrument for several reasons (Bom and Toren 2017; Bom 2018). In the first place, GMB starts with the language and concepts used by the population itself in relation to the problem, which reduces the Western influence on the agenda. We therefore facilitated the negotiation of the problem and the choice of the basic concepts with the help of an online survey, just ten days before the GM B sessions took place. The questionnaire can be found in the annexes of this book. A second advantage of GMB is that it promotes system thinking and searches for related variables, which really helps to make sense of the logic of the groups' discourses, and, 
more specifically, the identification of causal relations in the discourse. This also encourages a so-called holistic approach and prevents the population from concentrating on a limited number of aspects related to the issue at stake (Bleijenbergh, Korzilius and Verschuren 2011, 150). This points to a third advantage of GMB: the production of a causal loop diagram that forms the crucial stage of GM B (in this book we will simply refer to it as 'the model'). This model maps the causal relations between the important concepts and processes of the 'messy problem' as perceived by the participants. The function of the model and the way it is constructed was explained to the participants during the first session. The structuring effect of causal logic used in GMB is an instrument that enables the participants to contribute to the analysis of their own discourse. This diagram therefore gives deeper insight into the logic of the participants concerning the problem (Vennix 1996, 51-67). Apart from the concept models (discussed below), we present seven models in this book: one for each student and academic group from each of the three cities, as well as an extra model produced by the students from Kinshasa.

The second and third advantages of GMB mean that it is especially fruitful for the kind of systematic approach normally used in Western theology to study the relationship between science and faith. GMB produces a model that reflects some of the group's basic lines of thought. However, this does not imply that the model produced by GM в can be considered the systematic summary of the reconstructed discourse, or the outline of the major arguments. As the analyses in Chapters 4 and 5 show, the models are nevertheless very helpful for understanding the logic and cohesion of the studied discourses. Because the model built in a GMB session is the product of the whole group, it creates a system of relations between the major variables that is discussed and negotiated and is therefore intersubjective. This implies that the model produced is not the best possible systematic solution, but rather is the consensus of a group; in this case a group of African Christians involved in science. This reflects the process by which a great variety of (ecumenical) synods that have made decisions about theological questions over the past two millennia. These results are not systematic theology itself but do offer the basic material needed for systematic reflection.

Apart from GMB, we also make use of one round of focus groups which enables the interpretation of the data to be tested in the local groups, and a further round of focus groups which permits the local groups to express their proper understanding of the best ways forward. This implies that the data as summarized in the model are brought back to the groups to offer the opportunity of revision or confirmation. The student group from Kinshasa was the only one that proposed a revision of the model (see Chapters 4 and 5). The other 
groups wholeheartedly confirmed the model as a summary of their discourse. The research therefore remains one step removed from the action itself. In terms of the four voices of theology (Cameron et al. 2010), it focuses on the 'espoused theology' of the local groups but does not analyse the 'operant theology' implicit in their practices. Our focus on the participatory element rather than the action element is motivated by our interest in intercultural dialogue: the approaches to, and understandings of, the relationship between science and religion (which we discover through a survey, GMB, and focus groups) can more easily be brought into dialogue with Western perspectives. In contrast, proposals focused on action might be even more particular to the specific social contexts and therefore harder to relate to the Western context (Toren and Bom, 2018).

However, there are also some further questions about the use of GMB in our particular project. A causal loop diagram or model is a simplification of a comprehensive and complex debate on science and Christian faith. The relationships between the main concepts and processes are not limited to causality either. Exogenous factors, such as the diversity of the social, ethnic, and denominational backgrounds of the participants, the actual political and religious situations, and even the group's dynamics all play a role as well (as we elaborate on in Chapters 4-6), but are not visible in the model itself. A model must therefore be interpreted with constant reference to the discourses and cannot be isolated from what is said during the session and by whom; as we show in Chapters 4 and 5. The model is best understood as an entrance to the debate and helps us discover some basic systematic structures of the discourse. In this research, GMB mainly helps us to describe the discourse of the students.

\section{Layout of the Research}

We developed the specific use of GMB and the design of the research track in continuous dialogue with the experts from Nijmegen Management School. ${ }^{5}$ One of them, Dr. Hendrik Stouten, went with us on one of the roundtrips to the three African cities to coach the facilitator, and to assist in the process as a model builder. In this section we present the research track and discuss the specific adaptations we had to make because of the local situations.

5 See http://www.ru.nl/nsm/. Last visited on 15 of October 2018. 
In order to reconstruct, analyse, and evaluate the discourses of Christian MA students and academics on science and Christian faith from Abidjan, Kinshasa, and Yaoundé we decided to divide the field research into four stages. In first stage we conducted the online survey. The second stage was the GM B session. During the third stage the model that had been built was analysed in a focus group session. The last stage was a final evaluation in a second focus group session.

We will elaborate the description of each stage below.

\subsection{Scope and Selection of Research Population}

We limit this research to Christians within the academic communities of the three cities. From the perspective of espoused theology, it is somewhat strange to limit the population to people with an advanced academic formation. Nevertheless, we think it is important that participants have proper experience with science and scientific research. This last criterion led to the focus on MA students, because, at many African universities, BA students are not involved in research. In a way, the participants are experts; not so much in the debate on science and religion, but by their involvement in scientific activities. We also focussed on the practices of science, and not primarily on the theories of science and religion. However, we presumed that these persons would have a clear engagement with a particular way of acquiring (new) knowledge in science. This turned out to be a wrong presumption of these students (and probably also of MA students more generally). In Kinshasha and Yaoundé they argued that studying at MA level is also good for your career, and helps your family to make a social statement. Our limited scope excludes the churches' perceptions of science, as well as the broader appreciation of science in society. The narrow scope of the research is justified by the intercultural theological dialogue we want to initiate. From our perspective, the understanding of science and religion by scientists (students and academics) themselves also includes more specific inside knowledge about science, as is the case with the dialogue partner, the formal theology on science and religion from the North Atlantic world. Finally, we turn to the three cities. The selection of three cities helps to understand at least something of the diversity present in francophone Africa. Although the specific group we select is just a small part of society, the cultural, historical, and political differences between the three cities selected is impressive (as we elaborate on in Chapter 3). Although this makes it possible to test a hypothesis on the impact of French laïité, for example, it also results in disadvantages, such as very different local cultures. The cooperation with GBU-AF also restricted the population of the research, which we argue is dominated by evangelical Protestant voices. 
The selection of the participants was made in cooperation with Group Bibliques Universitaires (GBU), a Christian student movement that exists in most French-speaking countries and is related to the International Fellowship of Evangelical Students; ${ }^{6}$ we will come back to this organisation in the next chapter. This involved the internal power structure of the different national organisations of GBU in the selection process. To diminish the impact of the organisational power structure, we indicated strict selection criteria for the participants including: diverse denominational background and gender, diverse academic specialisation, and diverse ethnic belonging. In the annexes the lists of the participants can be found, including information regarding gender, academic specialisation, and denominational background. ${ }^{7}$ This diversity is not meant to be representative of the local situation but to create a diverse research population that contributes to a rich discourse. We also explicitly asked them to include students from other student movements, which they did. The local organisation proposed participants based on these criteria.

In most cases this resulted in a dominant participation by what we call 'evangelical Protestants'. These participants are members of traditional Lutheran, Presbyterian, Baptist, and Evangelical churches, etc. In most groups there are only a few Roman Catholics and Pentecostals. The student group in Kinshasa even lacked a Roman Catholic representative but did have a strong representation of Pentecostals. In the Kinshasa groups the diversity among the Pentecostals came to the fore. Two active participants in the student group, Gloire and Cardin, come from different Pentecostal backgrounds. Gloire is affiliated with a traditional Pentecostal denomination, the Assemblies of God, while Cardin identifies himself as a member of a so-called 'église de reveil'? The three categories we use to index denominational affiliation are therefore quite rough, and, to a certain extent, hide the variety of denominational backgrounds actually present. As we have already mentioned, our categorisation functions as an instrument to verify the diversity of the research population rather than to guarantee a representative sample. Additionally, the number of participants does not necessarily correspond with the effect of their influence on the discourse. The Roman Catholic contribution was crucial in the GMB session with the academics from Kinshasa, and Martha, a Pentecostal, was a

6 See https://ifesworld.org/en last visited on 15 October 2018.

7 Ethnic background was especially difficult to discover in Kinshasa (see Chapter 4). Therefore, we do not refer to ethnic background in the list of the participants (in the annexes), but ensured that in every group there was at least a variety of ethnic background among the participants, as becomes clear in Chapters 4 and 5 .

8 For more on neo Pentecostalism in Africa, see for example Ogbu Kalu African Pentecostalism: An Introduction (Oxford: Oxford University Press, 2008). 
leading voice during the GMB session with the academics from Yaoundé. In both cases, as well as in the case of the students from Kinshasa, the denominational background could be traced in the discourses, as we will show in Chapters 4 and 5. A nice example of the dominance of Protestant input was the (impartial) role given to the Bible and its interpretation in the discourse of the students from Yaoundé.

In terms of gender, men and women were only equally represented in the student group from Abidjan (nine women, eight men). All the other groups were male dominated, with the academic group from Abidjan (containing just one woman) and the academic group from Kinshasa (containing no women at all) having the lowest scores on the selection criteria. We discussed this with the leadership, who explained to us that especially among the academics it was difficult to find people who wanted to free themselves for a few hours for a research session. However, even more importantly, this gender bias reflects the general situation in important universities in the region. A good example of this is to be found on the website of the prestigious University Félix Houphouët Boigny, the home university of several participants from Abidjan. The website mentions that there are 60,000 students in all programs but only $10 \%$ of them are female. The percentage of women among the researchers is higher at $26 \%$, while the percentage of women among the professors is not mentioned. ${ }^{9}$ The academic group from Yaoundé had good participation by women, although this was not reflected in all the research sessions. The considerable participation by women was mainly realized in the third research session; in the first session only two women appeared alongside five men. The powerful performance of Martha during this first session was therefore striking (see Chapter 4). The gender biased composition of the groups helps to explain the timid attitude of the female participants, and this is seen during the first session with the students in Yaoundé (nine men, five women). This also offers insight into the very open dynamics during the first session with the students in Abidjan, as described in Chapter 5 . However, it is not so easy to understand its impact on the content of the discourses.

The diversity of academic specialisation we asked for was better realized, although in some groups certain disciplines had more influence. Most remarkable was the dominance of theology and philosophy among the academics in Kinshasa. Among the students from the same city there was a strong tendency towards applied sciences (trade, public works, electricity, etc.), which

9 See http://univ-fhb.edu.ci/index.php/ufhb/quelques-chiffres/ last visited on 15 October, 2018. If only $10 \%$ of the students are female, then the leadership of the GBU in Abidjan did an excellent job. 
influenced the discourse of the group considerably, as we argue in Chapter 5 . In general, the participation of students from the natural sciences was poor. Law and philosophy were strongly represented in the student group from Abidjan, which had a clear influence on the debate. Among the academics there was a better equilibrium between the natural sciences, social sciences, and humanities.

Finally, we reflect on the importance of ethnic background, and how this differed in the three cities. In Kinshasa the students were much less aware about their ethnic belonging and its traditions, but this was more important in Abidjan, and was a major theme in Yaoundé. In Chapter 3 we explain the political background to this, particularly with respect to Cameroon and Yaoundé. The selection of participants of different ethnicities was very well done here, because the generally more sceptical attitude of the Bamileke participants towards the importance of their cultural heritage as Christians contrasted nicely with the more harmonious approach of some participants from other ethnic backgrounds (see Chapters 4 and 5).

The research population is therefore diverse, but this diversity has its limitations, especially in relation to church background and academic specialisation. However, we never meant the research to be a representative sample. Instead, we aimed to create diversity within research groups. This diversity contributes to the richness of the GMB process, in which the discourse is negotiated by the group. In this way participants were challenged to contribute to a more general Christian understanding and a broader academic perspective.

\subsection{Research Track}

We started the field research with the online survey ten days before we visited the cities for the first research sessions with the participants in May 2015. The questionnaire served a double purpose. First, it helped the participants to focus on the content of the research sessions. It was therefore important to present this survey just before the first sessions. Second, we also wanted to acquire some relevant information about the participants' backgrounds, and, more specifically, on their major lines of thought concerning science and faith. We mainly asked for their reaction to several theses concerning the relation between science and faith; for example, "My faith is a hindrance to my study" (in the case of the MA students), and "University is a place where Christian faith can prosper" (both groups). The questionnaire for the students can be found in the annex; we used a slightly adapted version for the academics. The final questions, which ask for some keywords that capture what they argued earlier in the survey about science and faith, are fundamental for the research. We used the concepts gathered in the survey to make an example of a small model 
called a 'concept model', which we will expand on below. The participation in the survey varied in the groups. In this online survey, the participation of the students from Yaoundé was excellent; eighteen participants took part. The participation of students in Abidjan (eight) and Kinshasa (only two) was significantly lower. The participation of the academics was between seven and eleven. These differences can be explained by the local situations. In May, the situation in Abidjan was still chaotic due to the unrest at the university, and thus it was not easy to get in touch with the participants. In Kinshasa, students appeared to have very limited access to the internet.

Based on the information from the survey, our research team in the Netherlands construed a concept model (Richardson 2013), using the concepts chosen by the participants in the online survey. Because we are especially interested in the way the cultural context influences the model building, we made a separate concept model for each city with only a very small difference between the student and the academic models. The function of a concept model is twofold: a) It allows for an explanation of how model building works, and (b) it helps to start the debate with terms the participants have chosen themselves.

The second phase of the research consists of the GMB session. These sessions took place at the end of May and the beginning of June 2015. To avoid the university hierarchy having a huge impact through the dominance of the academics, we decided to apply GMB in two separate groups in every city; one for MA students and one for academics. The model construction involves two fundamental elements: the variables and the connecting arrows between those variables. In our research, we understand the variables as key concepts related to the practices of scientific engagement and the involvement of faith. After an explanation of our research, we started these sessions with an explanation of GMB. We used the presentation of a concept model, as mentioned above, which enabled the explanation of how model building functions with the help of crucial concepts selected by participants themselves through the survey. The concept model is very basic and normally consists of four to six variables. These variables are connected to each other with the help of arrows. GMB permits only two types of relation (arrow), a positive (indicated by the + sign at the side of the arrow in the models) or a negative (indicated by the - sign at the side of the arrow). The positive arrow indicates that the variables at both ends diminish or increase in the same direction. In contrast, the negative arrow indicates that the development of both variables moves in an opposite direction (see figure YS2 for example; the model of the students from Yaoundé in the annexes). Normally, the participants change the concept model significantly during the GMB session. It therefore has a mainly instrumental significance (i.e., to explain how GM B works). After this introduction, the model building 
session starts with the collection of the variables and the subsequent construction of a model (using the two types of arrows in order to establish lines of thought), and finally the cohesion of the discourse. As we explained, we used a survey to collect the variables for the concept model. However, at the beginning of the session itself, we did not use this list of variables but rather asked the participants to mention the concepts they perceived to be indispensable in the debate on science and faith. In this way, everyone was included and heard about the concepts at the start of the meeting.

The third stage took place a few months later, in October and November of 2015. We did not use GMB in this stage but did ask the participants to reconsider the models in focus group sessions. Hennie Boeije confirms the use of focus groups "when the communication and construction of certain knowledge is the main interest of the research" $(2010,64)$.

Furthermore, according to De Roest, focus group sessions are especially appropriate for theological inquiry, as they are in line with the relational character of God and faith $\left(2015,253^{-254}\right)$. The aim of these sessions was to confirm and analyse the models that had been built. Nearly all the models were confirmed with only the students from Kinshasa proposing some changes to the model they had earlier built (see Chapters 4 and 5). Unfortunately, the participants in the GMB sessions were not identical to those in the first focus groups. Only the student group in Yaoundé had very stable participation, and this was probably due to the efforts of the local team members of our project. In Chapters 4 and 5 we will describe the different local situations.

Apart from the confirmation of the model, the facilitator gave three 'challenge' questions to the groups in order to generate more insight into how the participants themselves understood the model. The first involved the presentation of a concrete case about a doctor who deals with science and faith in everyday life. Its purpose was to clarify how the participants would relate the model they had built to scientific practices. The case was based on an interview we had in one of the three cities during the early, explorative stage of the research. The case is as follows:

There is a doctor who is a professor of medicine and works in a university hospital somewhere in francophone Africa. When a patient comes to her desk, after listening to the patient's story, she makes her go through a series of exams and tests in order to diagnose the disease. However, in some cases she can't make a diagnosis because the outcomes of the exams don't point to a defined pathology. In that case she concludes there must be a spiritual problem and she decides to pray with the patient. 
The second challenging question was about the relation between the denominational background of the participants and the model, while the third concerned the relation between the model and the traditional cultures of the participants. These two questions were meant to explore the participants' reflections on how their context influences the model.

Finally, the fourth stage of the research took place a year later, in the autumn of 2016. Lamentably, we could not go to Kinshasa due to the unrest in the city at that time. However, this last stage consisted of a considerably shorter focus group session in order to evaluate the group's discourse, as reflected in the model, in the light of the models produced by the other groups during the research. In contrast to the focus group session in stage three, we discussed all of the six models produced during the research and started the evaluation of the discourses in a larger group before we had our research session. The idea was that the participants would be inspired by the views of others. The facilitator asked the groups if they could make a strength and weakness analysis of the model and indicate how their discourse on science and faith could be strengthened. This last question appeared hard to answer and none of the groups gave a clear answer.

All the research sessions were audio and video taped and totalled nearly 35 hours. The transcription of the sessions was done in Cameroon and supervised by the team members. We used Atlas-ti for the labelling and analysis of the documents. ${ }^{10}$ In the different chapters, we will refer to the Atlas-ti stored documents in the footnotes with a capital P, followed by a number from 1 to 20 . An additional number refers to the specific place within the indicated text; for example P12, 51. In this book we anonymize the research and use fictive names to refer to specific individuals. All participants were informed about the specific use we would make of the tapes and signed a consent form. The data is owned by the chair of intercultural theology at the Protestant Theological University. The taped and transcribed sessions are of course also the property of the participants, or at least an organisation from francophone Africa, such as GBU-AF. However, this appeared to be very difficult to actualise in accordance with Dutch law concerning privacy, etc. The ownership thus reflects the North Atlantic domination of science.

The reconstruction and analysis of the discourses can be found in Chapters 4 and 5 . We took Yaoundé as the principal case mainly because of the continuity of participation in the student group. Chapter 4 is dedicated to the role of cultural differences between African and Western in the different discourses.

Atlas-ti is a tool for qualitative research analysis; see Susanne Friese (2014). 
In Chapter 5 we focus on the approach and understanding of science and faith, relating this back to the outcomes of Chapter 4 . The models built by the participants during the first research sessions play an important role in the interpretation of the discourse. These models can be found in the annexes at the end of the book as figures with specific codes. For example, figure YS1 refers to the concept model that the researchers from the Netherlands construed based on the results of the online survey and used to start the session with the students in Yaoundé. Figure AS2 is the model built by the students from Abidjan, etc. In the case of the students group from Kinshasa there are three models, because during the second session this group decided to change the model they had built before; this altered model is called figure $\mathrm{KS}_{3}$.

For those interested, we give some basic information on how to read these models. Above we explained that there are three basic elements for model building: the variables (first selected by the group during the research session), positive arrows (indicated with + ) and negative arrows (indicated with -). A positive arrow indicates that the variable at the rear of the arrow contributes positively to the variable at the head of the arrow. The negative arrow indicates a negative contribution. Reading the model implies spelling out the different feedback loops in the model and studying how these loops relate to each other. For example, the students in Abidjan construed the simplest model of all the groups with just two feedback loops (see figure AS2). In their model, both feedback-loops have two negative arrows and are therefore reinforcing. Overall the three elements of variables, positive arrows, and negative arrows describe a process with the following content:

Feedback-loop $A A$ argues that more (knowledge of) truth leads to a positive contribution to the knowledge of the domain of study, which leads to a decrease in the experience of insecurity at the university. This positively affects the quality of the academic culture and that leads to an increase in truth, etc.

Feedback-loop $A B$ is quite similar, although it represents the dynamics of the knowledge of faith instead of the knowledge of science: more truth leads to more knowledge of faith, which lessens the experience of insecurity at the university. This strengthens the quality of academic culture and, therefore, leads to more truth, etc.

Feedback loops can either be reinforcing, like those in figure AS2, or balancing. Reinforcing loops have an even number of negative arrows, while balancing loops consist of an odd number of negative arrows. As an example, the model of the students in Yaoundé has very few reinforcing feedback loops. The balancing loops indicate that there is not an 
established understanding of the main issue in this group; this is elaborated on in Chapters 4 and 5 .

\subsection{Looking Back}

Looking back, we admit that we did not foresee all the consequences of the research track at the start. Perhaps the weakest point of the research was the planning of the sessions and the consequent discontinuity of the research population, especially in Abidjan and Kinshasa. Although we could guarantee that there were always at least three of the people who participated in the first session present in the latter sessions, in some cases the ownership of the discourse was not strongly felt, as is clear in the following chapters. It is, however, very remarkable that the student group from Yaoundé stayed intact during the whole period of the research. This is at least partly due to Lynda who worked at the project's office in Yaoundé. She was able to keep in contact with the participants and to encourage them to come to the next research session. In Abidjan the drop out among the students was substantial. We were told that those who left had found a job or gone to study elsewhere. However, the groups of academics also suffered from discontinuity, although not as much. However, thanks to the network of GBU new participants were found. In the case of the academics from Yaoundé, a newcomer appeared to play a very important role in helping to uncover more hidden layers in the discourse of the model building session. In general, however, the impact was less positive. It would have been far better if the research sessions had been organised within a shorter time span, for example within a month, instead of a year and a half. In any case, working with students is probably be most straightforward if one works within the limits of a semester.

This research would have been impossible without the help of local partners, in this case the student organisation GBU in the different countries (GBUCote d'Ivoire, GBU-RD Congo and GBEEC). In the first place, they offered us a broad national network of contacts, not only within their traditional evangelical peer group but also beyond. Additionally, the national staff, the board, and the organisational infrastructure were of incredible value. They were really interested in the results of our research, which made this project a shared enterprise. Above we have already highlighted the importance of the work of the local team member, Lynda Zegha. Her engagement helped to avoid a massive drop out among students in Yaoundé, and, although she could not do the same in the other two cities, her engagement with students and academics in Abidjan and Kinshasa made her an extremely valuable link with local organisations and the participants. Doing research in other cultural contexts is greatly improved by a local team member. 